\title{
The mating system and population genetic structure in a bird-pollinated mallee, Eucalyptus rhodantha
}

\author{
Jane F. Sampson, ${ }^{* \dagger}$ \\ Stephen D. Hoppert and \\ Sidney H. James*
}

\author{
* Department of Botany, The University of Western \\ Australia, Nedlands, Western Australia, 6009. \\ $\$$ Department of Conservation and Land \\ Management, Western Australian Wildlife Research \\ Centre, P.O. Box 51, Wanneroo, Western Australia, \\ 6065 .
}

The mating system and spatial genetic structure of the rare and endangered bird-pollinated mallee Eucalyptus rhodantha were investigated in a remnant stand, using progeny arrays and pollen assayed at four polymorphic allozyme loci. Comparisons of the genetic diversity within and between the pollen pools and maternal parents of two arbitrary subpopulations indicated the presence of spatial genetic heterogeneity which was not broken down by pollen flow. It was suggested that this is the result of a high level if inbreeding and limited pollen dispersal by birds. Estimates of outcrossing rate ranged between $\hat{t}=0.59$ and $\hat{t}=0.67$ and were at the low end of the range reported for other eucalypts. It was concluded that $E$. rhodantha has a mixed mating system with a significant proportion of selfpollination. Biparental inbreeding within small neighbourhoods probably also contributed to the high level of inbreeding. The low level of outcrossing observed in $E$. rhodantha was not consistent with the hypothesis that bird pollination leads to high levels of outcrossing in the Australian flora. However, the level of outcrossing achieved through bird pollination together with high levels of gene flow between populations contribute to the maintenance of the relatively high levels of diversity which characterise the dissected populations of this species.

\section{INTRODUCTION}

The mating system plays an important role in determining the genetic structure and evolutionary potential of plant populations (Allard, 1975; Brown et al., 1985). Interactions between population structure and the mating system have been investigated in several experimental (Ennos and Clegg, 1982, 1985; Ellstrand and Foster, 1983) and natural plant populations (Brown et al., 1975; Linhart et al., 1981; Shaw and Allard, 1981; Neale and Adams, 1985; Ritland and Ganders, 1985; Shea, 1987).

In Eucalyptus, estimates of mating system parameters have been based on progeny arrays analysed in terms of the mixed mating model (Fyfe and Bailey, 1951). The assumptions of this model are: (1) each mating event is the result of either a random outcross with a probability $t$ or a selffertilization with a probability $s=1-t$; (2) the probability of an outcross is independent of maternal genotype; (3) outcross pollen pool allele

† Present address: Department of Conservation and Land Management, Western Australian Wildlife Research Centre, P.O. Box 51, Wanneroo, Western Australia, 6065. frequencies are homogeneous among maternal parents; and (4) selection does not intervene between fertilisation and the determination of progeny genotypes (Brown and Allard, 1970; Clegg et al., 1978).

Several studies indicate that the assumptions of the mixed mating model are often violated in natural populations by spatial or temporal variation in pollen pool allele frequencies or by selection (e.g., Brown et al., 1975; El-Kassaby et al., 1987; O'Malley and Bawa, 1987). Spatial genetic differentiation is thought to be common in plant populations because plants are immobile as adults and pollen and seed dispersal may be limited giving rise to clustering of related individuals (Ehrlich and Raven, 1969; Levin and Kerster, 1974; Brown, 1979; Turner et al., 1982; Neale and Adams, 1985). No direct measurements of local genetic differentiation and its consequences in relation to mating behaviour have been published for species of Eucalyptus.

The mating systems of ten species from three of the nine informal subgenera of Eucalyptus listed by Pryor and Johnson (1971) have been investigated: five from Monocalyptus, four from Symphy- 
omyrtus and one from Corymbia. Estimates of $\hat{t}$ have been relatively consistent within the genus $(0 \cdot 70-0 \cdot 86$; Moran and Bell, 1983). Nine of these species have small flowers which are conventionally regarded as being either pollinated by insects or by a range of insects and vertebrates. The tenth species, Eucalyptus stoatei C. A. Gardn, is unusual amongst eucalypts in that it is predominantly if not exclusively pollinated by birds. The estimate of $\hat{t}$ reported for this species $(\hat{t}=$ $0 \cdot 82$; Hopper and Moran, 1981) was one of the highest so far reported in Eucalyptus.

Hopper and Moran (1981) pointed out that, like E. stoatei, most of the large-flowered, vertebrate-pollinated Western Australian eucalypts have dissected population structures. They suggested that this type of population structure favoured the evolution of bird pollination as a mechanism for maximising outcrossing and promoting genetic diversity. This suggestion was consistent with the hypothesis that bird pollination leads to high levels of outcrossing in the Australian flora (Paton and Ford, 1977; Bond and Brown, 1979; Ford et al., 1979; Hopper, 1981).

Gene flow within populations, mainly through pollen dispersal, is expected to be lower in birdpollinated, insect-pollinated or inbreeding plants than in wind-pollinated species. Genetic differentiation of subpopulations has, however, been demonstrated in both insect- and wind-pollinated plant species (Schaal, 1975; Linhart et al., 1981; Knowles, 1984; Loveless and Hamrick, 1984; Bos et al., 1986; Gregorius et al., 1986; Furnier et al., 1987; Waser, 1987) and one bird-pollinated eucalypt which occurs as discrete clumps (Moran and Hopper, 1987). In addition, several mating system studies have provided indirect evidence of genetic substructures within populations (Brown et al., 1975; Neale and Adams, 1985; Furnier and Adams, 1986; O'Malley and Bawa, 1987; Shea, 1987). There are, however, exceptions (Ennos, 1985; Dewey and Heywood, 1988) and we are not aware of any reports of genetic differentiation within continuous populations of outbreeding, bird-pollinated trees. Investigations of more birdpollinated species with dissected population structures are required to determine whether bird pollination is associated with high levels of outcrossing and with spatial differentiation within populations.

Eucalyptus rhodantha Blakely and Steedman is a member of the informal subgenus Symphyomyrtus. It is known only from remnant stands but probably had a regional $(150-600 \mathrm{~km})$ dissected distribution prior to land clearing. It is a small, spreading mallee and produces relatively few, large (up to $7.5 \mathrm{~cm}$ across), pendulous flowers with red filaments. Flowers are protandrous ( $\mathrm{McNee}, 1986)$ but the presence of flowers at different stages within the canopy of one mallee allows geitonogamous pollination. Like E. stoatei, it is pollinated primarily by birds (McNee, 1986).

The distribution of genetic diversity within and between two arbitrary subpopulations of $E$. rhodantha was investigated using allozyme markers. This study was combined with an investigation of the mating system in this bird-pollinated mallee, to contribute to an understanding of how the mating system affects the spatial distribution of genetic diversity within populations and to aid in the design appropriate strategies for conservation of this species.

\section{MATERIALS AND METHODS}

The study site was one of two stands of $E$. rhodantha approximately $500 \mathrm{~m}$ apart in an 80 ha remnant of heath vegetation in agricultural land. The western stand consists of about 180 mallees. The distribution of the plants is continuous but clumped and there are large distances between some groups and individuals. The stand was arbitrarily divided into five main subpopulations: one spread over a shallow rise outside the fenced section to the north, one on the west side of the stand, one in the north-east corner, one in the centre and one in the south-east corner of the stand. The arbitrary subpopulations on the western side (25 mallees; subpopulation 1) and in the north-east corner ( 20 mallees; subpopulation 2 ) were selected and the positions of plants plotted using ground surveys and aerial photographs. Individuals were identified from the position of stem origin and from leaf, bud and flower characteristics. The two subpopulations were approximately $170 \mathrm{~m}$ apart at their closest point.

At least five capsules were collected, where possible, from different branches of each plant. Capsules were bulked and seed was extracted by drying the capsules at room temperature. Three plants in subpopulation 1 and one plant in subpopulation 2 had no mature fruit. Pollen was collected from a majority of plants and used to determine maternal genotypes.

\section{Electrophoretic procedures}

Ten seeds per plant were germinated on moistened filter paper. Seedlings with emerged cotyledons 


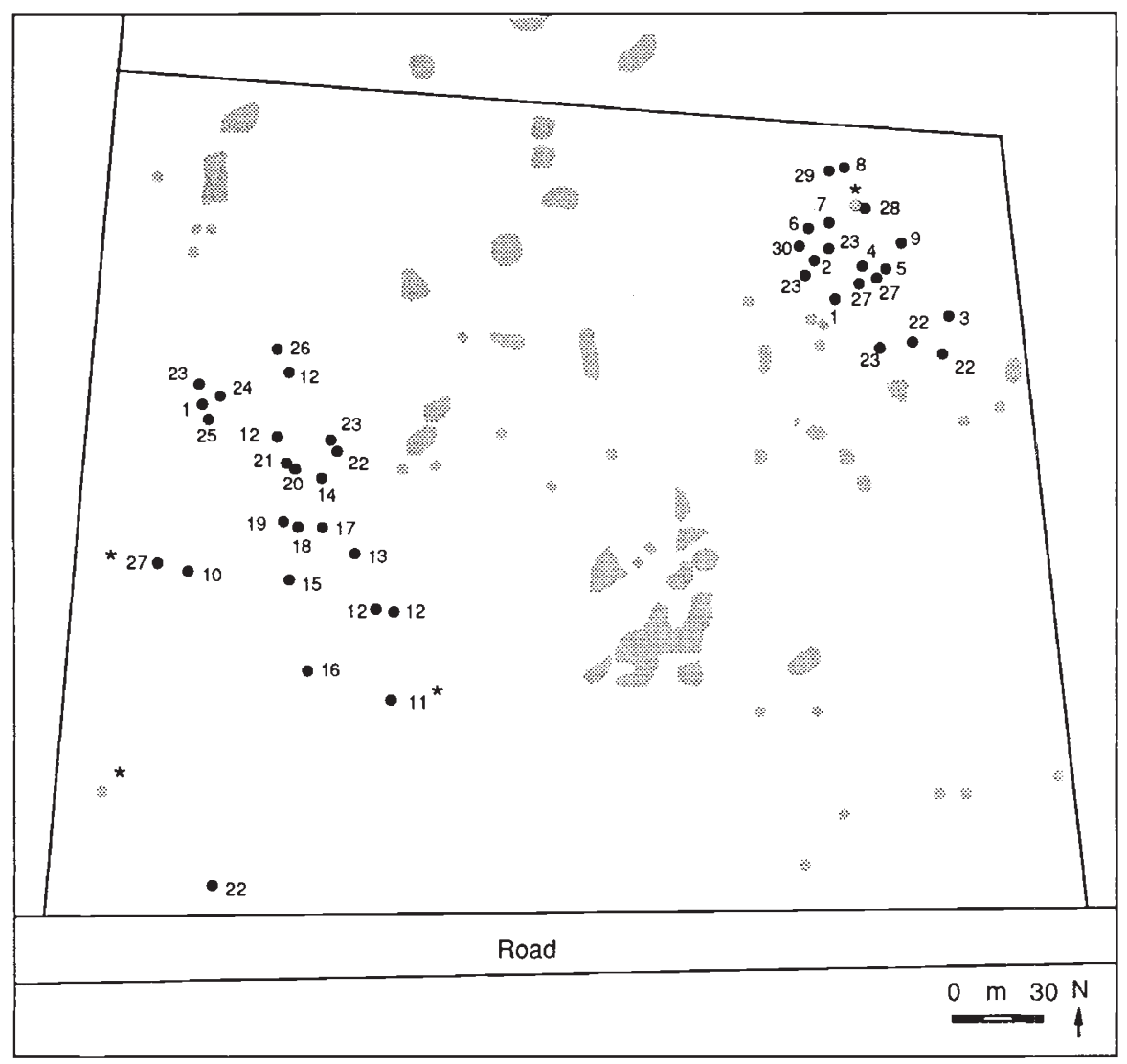

Figure 1 Diagrammatic rẹpresentation of the remnant stand showing the distribution of E. rhodantha and the multilocus genotypes of sampled plants in subpopulations 1 (west) and 2 (east). (O) Sampled plant, (अ Ehodantha. ( based on electrophoretic analyses of the loci $A d h-1$, Got-1, Got-2 and $M d h-2$ and are designated by numbers (e.g., 3). * No seed available. The scale is approximate.

and, when available, pollen samples were assayed for three enzyme systems (ADH, E.C. 1.1.1.1: GOT, E.C. 2.6.1.1: and MDH E.C. 1.1.1.37) encoding four loci (Adh-1, Got-1, Got-2 and $M d h-2)$ by methods described in Moran and Hopper (1983). Genetic interpretation of enzyme loci was based upon electrophoretic segregation patterns of progeny arrays from open-pollinated families and haploid pollen from maternal parents. Previous surveys of allozyme variation (Sampson, 1988) had demonstrated that the allele frequencies of these loci were suitable for the mating system estimation procedures used here.

Single-locus and multilocus estimates of the mixed mating model parameters for four loci ( $A d h$ 1, Got-1, Got-2, $M d h-2)$ and their variances were obtained using the computer programmes developed by K. Ritland (Ritland and Jain, 1981).

\section{RESULTS}

\section{Adult and progeny allelic and genotypic frequencies}

Maternal genotypes were determined from pollen samples for 24 of the 41 mallees from which seed was collected. For the remainder, maternal parent genotypes were inferred from arrays of at least ten progeny per plant by the method of Brown and Allard (1970) using the computer program of Ritland and Jain (1981).

Significant differences $(P<0.05)$ between allele frequencies in the maternal parents and pollen pool at loci within subpopulations were determined by comparing the bounds of their confidence intervals. Maternal parents allele frequencies differed significantly at the 95 per cent level from pollen pool allele frequencies in four 
Table 1 Allele frequencies for maternal parents and outcrossing pollen gene pools for two subpopulations and for data pooled over subpopulations

\begin{tabular}{|c|c|c|c|c|c|c|c|}
\hline \multirow[b]{2}{*}{ Locus } & \multirow[b]{2}{*}{ Allele } & \multicolumn{2}{|l|}{ Subpopulation 1} & \multicolumn{2}{|l|}{ Subpopulation 2} & \multicolumn{2}{|c|}{ Pooled subpopulations 1 and 2} \\
\hline & & Maternal parents & Pollen & Maternal parents & Pollen & Maternal parents & Pollen \\
\hline \multirow[t]{2}{*}{$A d h-1$} & 2 & $0.50(0.08)$ & $0.77(0.04)^{*}$ & $0.58(0.08)$ & $0.71(0.04)$ & $0 \cdot 54(0 \cdot 06)$ & $0.73(0.03)^{*}$ \\
\hline & 4 & $0.48(0.08)$ & $0.21(0.01)^{*}$ & $0.29(0.07)$ & $0 \cdot 23(0.01)$ & $0.39(0.05)$ & $0.23(0.02)^{*}$ \\
\hline \multirow[t]{2}{*}{ Got-1 } & 1 & $0.59(0.07)$ & $0 \cdot 70(0.01)$ & $0 \cdot 18(0.06)$ & $0 \cdot 34(0 \cdot 01)^{*}$ & $0.40(0 \cdot 05)$ & $0.54(0.002)^{*}$ \\
\hline & 2 & $0.39(0.07)$ & $0.29(0.01)$ & $0.76(0.07)$ & $0.63(0.01)$ & $0.56(0.05)$ & $0.43(0.02)^{*}$ \\
\hline \multirow[t]{2}{*}{ Got-2 } & 1 & $0.43(0.07)$ & $0.44(0.01)$ & & & $0.56(0.05)$ & $0.42(0.01)^{*}$ \\
\hline & 2 & $0.48(0.08)$ & $0.51(0.03)$ & $0.63(0.08)$ & $0.63(0.06)$ & $0.40(0.02)$ & $0.55(9 \cdot 01)^{*}$ \\
\hline \multirow[t]{2}{*}{$M d h-2$} & 1 & $0.16(0.06)$ & $0.27(0.01)^{*}$ & & & $0.19(0.04)$ & $0.21(0.003)$ \\
\hline & 2 & $0.82(0.06)$ & $0.70(0.01)^{*}$ & $0.76(0.07)$ & $0.96(0.02)^{*}$ & $0.79(0.04)$ & $0.78(0.01)$ \\
\hline
\end{tabular}

The most common allele for diallelic loci and the two most common alleles for triallelic loci are given. Standard errors in parentheses. * Significant differences $(P>0.05)$ between maternal parents and pollen pool allele frequencies within subpopulations.

of the eight comparisons in subpopulation 1 , two of the six comparisons in subpopulation 2 and six of the eight comparisons in the pooled data (table 1). The data indicate that the maternal plants do not contribute equally to the pollen pool at all loci in both the subpopulations.

Wright's Fixation Index ( $F$; Wright, 1969) and variances were estimated at each locus for both progeny $(F)$ and adult mallees (maternal, $F_{m}$ ) by the methods of Brown et al. (1975) and Phillips and Brown (1977), respectively (table 2). The less frequent allelic classes were pooled to give diallelic data. Estimates of the variances of mean $F$ and mean $F_{m}$ values were obtained by assuming that loci were statistically independent. Variances of the means were then formulated as the means of the separate variances divided by the number of loci (Brown and Weir, 1983). While estimates varied between loci, they were significantly positive in progeny and not significantly different from zero in the adult maternal plants in both subpopulations.

\section{Genetic differentiation among subpopulations}

Contingency $\chi^{2}$ values (Workman and Niswander, 1970) were calculated to test for homogeneity of allele frequencies in the maternal parents and pollen pools in the subpopulations. Individual locus and total contingency $\chi^{2}$ values indicated significant heterogeneity of pollen pool allele frequencies between the two subpopulations $\left(\chi_{(8)}^{2}=197 \cdot 254, P<0 \cdot 01\right)$. Heterogeneity in maternal parent frequencies was significant for only one locus, Got $-1\left(\chi_{(2)}^{2}=14.039, P<0.01\right)$ but the total value for the four loci was also significant $\left(\chi_{(8)}^{2}=\right.$ $25.537, P<0 \cdot 01)$. This suggests higher genetic differentiation between the pollen than between the maternal parent subpopulations.

In order to investigate further the extent of genetic differentiation between subpopulations, Nei's (1973) hierarchical gene diversity statistics were calculated using maternal parents and pollen pool allele frequencies. Estimates of $G_{S T}$ (table 3) also demonstrated genetic differentiation. Esti-

Table 2 Estimates of Wright's Fixation Index for each locus in the progeny $(F)$ and for the maternal trees $\left(F_{m}\right)$ in the subpopulations

\begin{tabular}{|c|c|c|c|c|}
\hline \multirow[b]{2}{*}{ Locus } & \multicolumn{2}{|c|}{ Subpopulation 1} & \multicolumn{2}{|c|}{ Subpopulation 2} \\
\hline & $F$ & $F_{m}$ & $F$ & $F_{m}$ \\
\hline$A d h-1$ & $-0.01(0.07)$ & $-0 \cdot 82(0 \cdot 12)^{*}$ & $0.04(0.07)$ & $-0 \cdot 08(0 \cdot 23)$ \\
\hline Got-1 & $0.34(0.08)^{*}$ & $0.44(0.20)^{*}$ & $0.03(0.07)$ & $-0.02(0.23)$ \\
\hline Got-2 & $0.19(0.07)^{*}$ & $-0.18(0.21)$ & $0.23(0.08)^{*}$ & $0.36(0.19)$ \\
\hline$M d h-1$ & $0.37(0 \cdot 10)^{*}$ & $0.08(0.23)$ & $0.24(0 \cdot 10)^{*}$ & $-0.12(0.23)$ \\
\hline Mean & $0.22(0.04)^{*}$ & $-0 \cdot 12(0 \cdot 10)$ & $0.14(0.04)^{*}$ & $-0 \cdot 12(0 \cdot 11)$ \\
\hline
\end{tabular}

* Rejection of the null hypothesis that $F=0$ at the 5 per cent level. Standard errors in parentheses. 
Table 3 Total genetic diversity $\left(H_{T}\right)$ and the proportion of diversity between the adult (maternal tree) and pollen pool subpopulations of $E$. rhodantha at four loci

\begin{tabular}{llllll}
\hline & \multicolumn{2}{l}{$\begin{array}{c}\text { Adults (maternal } \\
\text { plants) }\end{array}$} & & \multicolumn{2}{l}{ Pollen } \\
\cline { 2 - 3 } \cline { 5 - 6 } Locus & $H_{T}$ & $G_{S T}(\%)$ & & $H_{T}$ & $G_{S T}(\%)^{*}$ \\
\hline Adh -1 & 0.681 & 20.5 & & 0.443 & 10.7 \\
Got -1 & 0.523 & 14.9 & & 0.516 & 11.8 \\
Got -2 & 0.535 & 1.7 & & 0.515 & 1.1 \\
Mdh-1 & 0.333 & 0.7 & & 0.303 & 10.0 \\
Mean & 0.518 & 9.5 & & 0.444 & 8.4 \\
\hline
\end{tabular}

$H_{T}$, total genetic diversity. $G_{S T}$, mean proportion of diversity between subpopulations.

* Calculated before rounding.

mates were relatively high when compared with those of a range of plant species with mixed mating $\left(\% G_{S T}\right.$ mean, $2 \cdot 0$; range $\left.1 \cdot 0-3 \cdot 8\right)$ or predominantly outcrossing ( $\% G_{S T}$ mean, $4 \cdot 1$; range, 0.3-14.8) mating systems (reviewed in Loveless and Hamrick, 1984). While estimates of $G_{S T}$ between subpopulations of $E$. rhodantha are based on only four polymorphic loci, many of the estimates in the above review were also based on low numbers of loci, so comparisons may still be meaningful. Loveless and Hamrick (1984) found that, for both selfing and outcrossing species, $G_{S T}$ values between populations were approximately twice those between population subdivisions. The estimates of $G_{S T}$ between subpopulations of maternal parents and pollen pools were approximately half that between remnant stands of $E$. rhodantha determined for progeny at the same four loci $\left(H_{T}=0.536, \% G_{S T}=16.6\right.$; Sampson 1988). Estimates of genetic differentiation based on the maternal parents and pollen pools were similar suggesting that genetic differentiation between subpopulations was not broken down by pollen flow.

\section{Spatial genotypic distribution and structure}

The spatial distribution of plants and codes indicating their multilocus genotypes are illustrated in fig. 1. Thirty different multilocus genotypes were found in the 41 different plants for which genotypes could be determined; 19 in subpopulation 1 and 15 in subpopulation 2 . In three cases, mallees next to each other that were assumed to be different individuals from the position of origin of their stems, were genotypically identical for the loci surveyed. These individuals may have been clones since $E$. rhodantha can reproduce vegetatively from an underground lignotuber.

\section{Linkage disequilibrium}

Independent segregation has been demonstrated between Ahd-1, Got-2 and Mdh-2 in Eucalyptus regnans F. Muell. (Moran and Bell, 1983) and descriptions of these loci in the above paper suggest that they are equivalent to those reported in E. rhodantha (Sampson, 1988). Regular Mendelian inheritance and independent assortment between Adh-1, Got-1 and Mdh-2 has been demonstrated in the presumptive selfed progeny of an isolated specimen of E. rhodantha (Sampson, 1988). Test cross data for E. rhodantha were not available and random gametic union could not be assumed since estimates of $F$ values demonstrated departures from Hardy-Weinberg frequencies at several loci. In such circumstances Weir (1979) and Weir and Cockerham (1979) recommend the estimation of Burrow's composite measure $\Delta_{i k}$ of linkage disequilibrium. This composite measure was estimated for pair-wise combinations of loci by the formula given in Brown and Weir (1983).

Significant disequilibrium was detected between some combinations of loci in subpopulation 2 and in the pooled data but the distribution of disequilibrium between subpopulations was not consistent (table 4). Several factors may produce linkage disequilibrium. These include inbreeding or asexual reproduction, genetic drift, mutation, migration and epistasis (Hedrick et al., 1978). Since there may be correlation between estimates of $\hat{t}$ based upon loci which exhibit linkage disequilibrium, the significant disequilibrium observed in subpopulation 2 and in the pooled data may bias variances of estimates of outcrossing for these samples.

\section{Outcrossing rates}

Single-locus and multilocus estimates of outcrossing rates are presented in table 5. All estimates differed significantly from random mating $(\hat{t}=1)$ and from complete selfing $(\hat{t}=0)$. The single-locus data generated expected numbers of progeny less than one and were therefore not suitable for $\chi^{2}$ analyses to test goodness of fit with the expectations of the mixed mating model. Fisher's heterogeneity $\chi^{2}$ test (Rao, 1973), used to test for heterogeneity of $\hat{t}$ over loci, indicated that there were significant differences among single-locus estimates of $\hat{t}$ when the subpopulations were analysed separately, but not when pooled. 
Table 4 Estimates of Burrow's composite measure of linkage disequilibrium $\left(\hat{\Delta}_{i k}\right)$ between four allozyme loci in progeny from two subpopulations together with estimates for pooled data

\begin{tabular}{lllllll}
\hline & Loci & & & & \\
\cline { 2 - 6 } Subpopln. & Adh-1/Mdh-2 & Adh-1/Got-1 & Adh-1/Got-2 & Mdh-2/Got-1 & Mdh-2/Got-2 & Got-1/Got-2 \\
\hline 1 & $0.016(0.015)$ & $-0.014(0.019)$ & $-0.033(0.018)$ & $-0.004(0.017)$ & $0.022(0.016)$ & $0.030(0.021)$ \\
2 & $0.013(0.015)$ & $-0.041(0.016)^{*}$ & $-0.054(0.020)^{*}$ & $0.016(0.014)$ & $-0.077(0.016)^{*}$ & $0.002(0.017)$ \\
pooled & $0.015(0.009)$ & $-0.068(0.014)^{*}$ & $-0.044(0.014)^{*}$ & $0.002(0.012)$ & $-0.024(0.011)^{*}$ & $0.025(0.015)$ \\
\hline
\end{tabular}

$\hat{\Delta}_{i k}$, Unbiased estimate, see text. Standard errors in parentheses.

${ }^{*}$ Rejection of the null hypothesis that $\hat{\Delta}_{i k}=0$ at the 5 per cent level.

Arithmetic and minimum variance mean outcrossing rate $(\hat{i})$ values over loci were calculated using the formula given by El-Kassaby et al. (1987). The mean single-locus and multilocus estimates of $\hat{t}$ were not significantly different from each other. Pooling of data from subpopulations 1 and 2 imparted a slight downward bias of the arithmetic mean $\hat{t}$, a slight upward bias of the minimum variance mean $\hat{t}$ and a downward bias of the multilocus estimate of $\hat{t}$. This variation is to be expected since allele frequencies of the subpopulations were significantly different at all loci in the progeny. The largest change was at the Got-1 locus. Again, this is anticipated since Got-1 was the only locus at which there was a significant difference in allele frequencies in the adults. Overall, these observations tend to confirm that, with respect to genetic and reproductive behaviour, there was some differentiation between the two subpopulations.

The multilocus estimates of outcrossing rate in E. rhodantha were greater than the minimum variance mean single-locus estimates of $\hat{t}$ for all subpopulations suggesting that some inbreeding other than selfing occurs.
In order to test for any local heterogeneity of allelic frequencies, the number of detectable outcrosses compared with homozygous progeny for each homozygous mother was entered in a $2 \times \mathrm{m}$ contingency table, where $m$ was the number of maternal plants homozygous for a given locus in each sample (Brown et al., 1975). The heterogeneity $\chi^{2}$ was calculated between these families and indicated significant heterogeneity at the $M d h-2$ locus in subpopulation 1, Got-1 in subpopulation 2, and Got-2 and Mdh-2 in the pooled data (table 6).

\section{DISCUSSION}

\section{Spatial genetic structure}

Comparisons of maternal parent allele frequencies, pollen pool allele frequencies and genetic differentiation estimates between the two arbitrary subpopulations of $E$. rhodantha indicate that genetic divergence has occurred between different parts of the stand.

Since the age of mallees is difficult to determine (Wellington et al., 1979), the possibility that

Table 5 Single locus and multilocus estimates of outcrossing $(\hat{t})$ calculated from progeny genotype arrays for two subpopulations and for pooled data

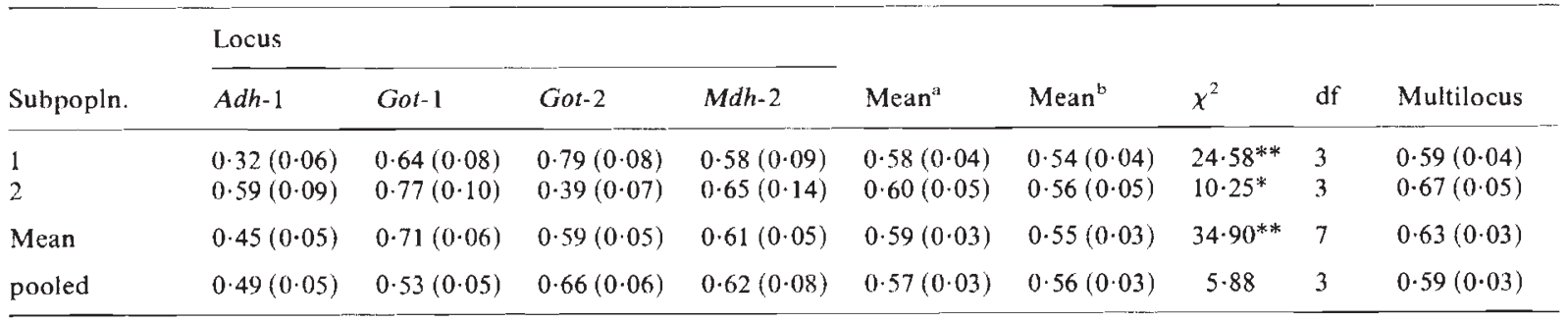

Standard errors in parentheses.

${ }^{*} P<0.05$.

** $P<0.01$ for $\chi^{2}$ heterogeneity of single-locus $\hat{t}$ over loci.

${ }^{a}$ Arithmetic mean.

${ }^{\mathrm{b}}$ Minimum variance mean, see text. 
Table 6 Heterogeneity $\chi^{2}$ of frequencies of detectable outcrosses among progeny genotype arrays of homozygous maternal genotypes at four loci in subpopulations together with estimates for pooled data

\begin{tabular}{|c|c|c|c|c|c|c|c|c|}
\hline \multirow[b]{3}{*}{ Subpopulation } & \multicolumn{8}{|c|}{ Locus } \\
\hline & \multicolumn{2}{|c|}{ Adh-1 } & \multicolumn{2}{|l|}{ Got-1 } & \multicolumn{2}{|l|}{ Got-2 } & \multicolumn{2}{|l|}{$M d h-2$} \\
\hline & $\chi^{2}$ & df & $\chi^{2}$ & $\mathrm{df}$ & $\chi^{2}$ & $\mathrm{df}$ & $\chi^{2}$ & df \\
\hline 1 & - & & 12.97 & 13 & $6 \cdot 33$ & 5 & $26 \cdot 02^{*}$ & 14 \\
\hline 2 & $3 \cdot 75$ & 5 & $18 \cdot 6^{*}$ & 10 & $4 \cdot 62$ & 5 & $9 \cdot 17$ & 10 \\
\hline $1+2$ pooled & $4 \cdot 04$ & 6 & $35 \cdot 59$ & 25 & $25 \cdot 48^{*}$ & 12 & $57 \cdot 17^{* *}$ & 25 \\
\hline
\end{tabular}

* Rejection of the null hypothesis that there is no between family heterogeneity at the 5 per cent level. ${ }^{* *}$ At the 1 per cent level. df, degrees of freedom.

heterogeneity arose between different age classes which were exposed to different selective pressures during their early years cannot be excluded. Another possible cause of the differentiation, microhabitat selection, was not investigated but observations suggest that heterogeneity of the stand's physical environment is limited.

A more likely explanation of the spatial heterogeneity observed in $E$. rhodantha is localised genetic drift occurring because of restricted dispersal of pollen by birds and a high level of inbreeding. Investigations suggest that gene flow between populations is high in E. rhodantha (Sampson, 1988) but this does not eliminate the possibility that local gene flow within populations could be limited, permitting local genetic differentiation (Levin 1981; Loveless and Hamrick, 1984). The high $G_{S T}$ values found between both the maternal parent and the pollen pool subpopulations and the high level of inbreeding reported here, together with estimates of pollen dispersal based on pollinator movements (McNee, 1986), suggest that gene flow through pollen dispersal within the study area is limited.

Seed dispersal distances were not quantified in $E$. rhodantha but seeds are slightly winged and may be blown about by the wind and are also harvested by ants. Levin and Kerster (1974) suggested that the dispersal of the majority of windborne seeds is restricted and there is evidence of family structure in populations of several conifer species with wind-disseminated seeds (Linhart et al., 1981; Knowles, 1984; Furnier and Adams, 1986). Therefore, while wind-dissemination of $E$. rhodantha seeds and bird pollination may permit gene flow over large distances, gene flow within the relatively undisturbed stand is probably limited and permits the development of genetically heterogeneous neighbourhoods of related individuals.
The high $G_{S T}$ values observed in both the pollen pool and maternal parents in bird-pollinated and relatively inbred $E$. rhodantha contrast with observations in an outcrossing $(\hat{t}=0.98)$ windpollinated grass Cynosurus cristatus L. (Ennos, $1985)$ where $G_{S T}$ values among adult subpopulations were very low and even lower among pollen pool subpopulations. Ennos (1985) concluded that substantial pollen flow in the grass prevents the development of signficant genetic differentiation through random genetic drift in different areas of the same population. Gene flow within populations may be expected to be less in a bird-pollinated species than in an outcrossing wind-pollinated species so that the likelihood of differentiation through drift is increased.

\section{Violations of the mixed mating model}

In a spatially heterogeneous population, neighbours may be related or genetically similar because they occupy the same habitat and have been subjected to the same selection regime. Outcrossing between neighbours can then result in "effective" selfing because of the genetic similarity between mates relative to the entire population (Ritland and Ganders, 1985). The mixed mating model assumption that outcross pollen pool allele frequencies are homogeneous over maternal parents is violated by spatial or temporal heterogeneity in these frequencies or if outcrosses share paternity (Ennos and Clegg, 1982; Schoen and Clegg, 1984).

Single-locus estimates of $\hat{t}$ are biased down. ward by any form of inbreeding including con. sanguineous mating. Multilocus procedures are theoretically less affected by violation of the mixed mating model assumptions and discriminate more efficiently between selfed and outcrossed matings. A measure of the total effect of inbreeding other 
than selfing can therefore be made by comparing multilocus and single-locus estimates of $\hat{t}$, but comparisons suffer from the large standard errors associated with estimates of $\hat{t}$ (Shaw and Allard, 1982). In E. rhodantha, the differences between single-locus estimates of $\hat{t}$ and comparisons of multilocus and single-locus estimates suggested that some of the deviation from panmixia was due to biparental inbreeding.

The significant heterogeneity of gene frequencies in the pollen pools sampled by maternal parents in both subpopulations and in the pooled data also indicated violation of mixed mating model assumptions. Differences in progeny genotype frequencies among maternal genotypes arise if the probability of outcrossing varies from tree to tree and/or there are differences between trees in the allele frequencies of their pollen pools (Brown et al., 1975). Heterogeneity in the pollen pools of individual trees may arise because of clustering of similar genotypes, or from temporal changes in pollen pool allele frequencies throughout the flowering season. Temporal heterogeneity has been detected in the study area (Sampson, 1988).

If the variation in allele frequencies in the outcross-pollen pool of plants was the major cause of departures from complete outcrossing, then one would expect a relationship between the level of apparent selfing and the level of heterogeneity because both would be measures of the correlation between uniting gametes (Brown et al., 1975). Significant heterogeneity was observed at different loci in different stands but high heterogeneity was not associated with low estimates of $\hat{t}$; in some instances high heterogeneity was associated with the highest estimate of $\hat{t}$. Therefore it seems unlikely that variation in pollen gene frequencies between maternal plants resulting from spatial clustering of similar genotypes or temporal variation in pollen gene frequencies were the main causes of the departures from panmixia observed in E. rhodantha. It may be concluded that self-pollination contributed significantly to the level of inbreeding in E. rhodantha.

When pollen deposited on the stigma is derived from only one or a few previously visited plants, many of the seeds will be full siblings. In such circumstances, maternal genotypes may be incorrectly inferred and estimates of $\hat{t}$ based on the mixed mating model will be biased down (Schoen and Clegg, 1984). The possibility of this occurring and affecting results in E. rhodantha was reduced for several reasons. Firstly, a majority of maternal genotypes were known from pollen samples.
Secondly, flowers may be visited numerous times by pollinators (McNee, 1986) and, thirdly, capsules were normally collected from widely spaced branches and were therefore likely to have arisen from different pollination events.

The change in $F$ values in $E$. rhodantha from positive in the progeny to around zero in the maternal adult plants suggests that selection favouring heterozygous, presumably outcrossed, progeny may contribute to the maintenance of a mixed mating system in E. rhodantha. Phillips and Brown (1977) and Moran and Brown (1980) made similar suggestions for Eucalyptus pauciflora Sieb. ex Spreng. and Eucalyptus delegatensis R. T. Bak., respectively. Selection favouring heterozygotes may also occur in E. stoatei (Hopper and Moran, 1981), Eucalyptus kitsoniana (Luehm.) Maiden (Fripp, 1982) and in Eucalyptus crucis Maiden (Sampson et al., 1988). Such selection, operating between fertilisation and the point at which seedlings are assayed, may have contributed to an upward bias in estimates of $\hat{t}$ in E. rhodantha.

\section{Comparisons with other eucalypts}

The multilocus estimate of outcrossing rate in subpopulation $1(\hat{t}=0.59)$ probably represent the least biased estimate of outcrossing in a natural population of E. rhodantha since multilocus estimates of $\hat{t}$ are less affected by the violations of the mixed mating model which have been shown to occur in E. rhodantha. Furthermore, no disequilibrium was detected within this subpopulation.

The breeding system of $E$. rhodantha is thus a mixed mating system with predominant outbreeding but with a significant component of inbreeding. Predominant outcrossing has been reported in other eucalypts (Brown et al., 1975; Phillips and Brown, 1977; Moran and Brown, 1980; Hopper and Moran, 1981; Fripp, 1982; Yeh et al., 1983; Moran and Bell, 1983).

The estimate of $\hat{t}$ in E. rhodantha was somewhat lower than those reported for many primarily outcrossing plant species (Schemske and Lande, 1985 ) and it is the lowest so far reported in Eucalyptus with two exceptions. Firstly, a multilocus estimate of outcrossing in a small stand of E. rhodantha isolated in agricultural land was $\hat{t}=0.26$ (Sampson, 1988) and secondly, Fripp et al. (1987) reported a mean single-locus $\hat{t}$ value of 0.52 in $E$. regnans. However, the sampling procedures used in these studies were unusual in that the seed samples came from a small isolated stand of trees and, in the case of E. regnans, from a single seed crop set the previous year. 
The majority of estimates made previously for eucalypts have been mean single-locus estimates, often based on loci detected in seeds, and the sampling procedures used were different to those used in the study of $E$. rhodantha reported here (Brown et al., 1975; Phillips and Brown, 1977; Hopper and Moran, 1981; Moran and Brown, 1980; Fripp, 1982; Yeh et al., 1983). The $\hat{t}$ estimated from seedling loci for $E$ rhodantha in subpopulation 1 would be biased up relative to estimates for other eucalypts because selection may have occurred between the seed and seedling stage and because bias due to sampling across genetically heterogeneous subpopulations was minimised. With these differences in mind, the estimate for the natural stand of E. rhodantha is indeed low and indicates a remarkable amount of selfing.

Hopper and Moran (1981) suggested that the evolution of bird pollination in eucalypts may represent the evolution of a system to promote outcrossing and hybridity. These authors suggest that bird pollination may provide a mechanism whereby the deleterious consequences of inbreeding in the small dissected populations which characterise E. rhodantha and most of the other large flowered vertebrate pollinated Western Australian eucalypts are reduced. A "pursuit of hybridity" in isolated populations is thought to have been a major force in the evolution of cytogenetic and breeding system variants in isolated granite rock populations of Isotoma petraea F. Muell. (James, 1965, 1970; Beltran and James, 1974) and many other members of the Australian flora (James, 1981; James and Hopper, 1981).

The low level of outcrossing estimated for $E$. rhodantha is not consistent with the hypothesis that bird pollination leads to high levels of outcrossing in the Australian flora (Paton and Ford, 1977; Bond and Brown, 1979; Ford et al., 1979; Hopper, 1981). However, the level of outcrossing and the high gene flow between populations achieved through bird pollination are part of a genetic system by which the relatively high level of allozyme diversity found within the dissected populations of this species is maintained.

In conclusion, E. rhodantha has a mixed mating system with predominant outcrossing but a significant proportion of self-pollination. A high level of inbreeding and limited gene flow within populations has given rise to the formation of genetically heterogeneous neighbourhoods. Biparental matings within neighbourhoods also probably contribute to a remarkable level of inbreeding in this species.
Acknowledgements We thank G. J. Watts for field assistance, S. McNee for access to unpublished data, Dr K. Ritland for his outcrossing program, Dr G. Moran and Mr C. Bell for advice on use of the program, Dr A. H. D. Brown and Dr D. Coates for their comments on the original manuscript and the referees for their constructive suggestions. This research was undertaken whilst J.F.S. was the recipient of an Australian Commonwealth Postgraduate Research Award and was financially supported by the University of Western Australia and the Western Australian Department of Conservation and Land Management.

\section{REFERENCES}

AllARD, R. W. 1975. The mating system and microevolution. Genetics, 79, 115-126.

BELTRAN, I. C. AND JAMES, S. H. 1974. Complex hybridity in Isotoma petraea. IV. Heterosis in interpopulational heterozygotes. Aust. J. Bot, 22, 251-264.

BOND, H.W. AND BROWN, W. L. 1979. The exploitation of floral nectar in Eucalyptus incrassata by honeyeaters and honeybees. Oecologia, 44, 105-111.

BOS, M., HARMENS, H. AND VRIELING, K. 1986. Gene flow in Plantago I. Gene flow and neighbourhood size in P. lanceolata. Heredity, 6, 43-54.

BROWN, A. H. D. 1979. Enzyme polymorphism in plant populations. Theor. Pop. Biol. 15, 1-42.

BROWN, A. H. D. AND ALLARD, R. W. 1970. Estimation of the mating system in open-pollinated maize populations using isozyme polymorphisms. Genetics, 66, 133-145.

BROWN, A. H. D. AND WEIR, B. A. 1983. Measuring genetic variability in plant populations. In Tanksley, S. D. and Orton, T. J. (eds.) Isozymes in Plant Genetics and Breeding, Elsevier, Amsterdam, pp. 219-239.

BROWN, A. H. D., BARRETT, S. C. H. AND MORAN, G. F. 1985. Mating system estimation in forest trees: models methods and meanings. In Gregorius, H. R. (ed.) Population Genetics of Forestry, Lecture Notes in Biomathematics, vol. 60, Springer-Verlag, Berlin, pp. 32-49.

BROWN, A. H. D., MATHESON, A. C. AND ELDRIDGE, K. G. 1975. Estimation of the mating system of Eucalyptus obliqua L'Hérit. by using allozyme polymorphisms. Aust. J. Bot., 23, 931-949.

CLEGG, M. T., KAHLER, A. L. AND ALLARD, R. W. 1978. Estimation of life cycle components of selection in an experi. mental plant population. Genetics, 89, 765-792.

DEWEY, S. E. AND HEYWOOD, J. S. 1988. Spatial genetic structure in a population of Psychotria nervosa. I. Distribution of genotypes. Evolution, 42, 834-838.

EHRLICH, P. R. AND RAVEN, P. H. 1969. Differentiation of populations. Science, 179, 243-250.

EL-KASSABY, Y. A., MEAGHER, M. D., PARKINSON, J. AND PORTLOCK, F. T. 1987. Allozyme inheritance, heterozygosity and outcrossing rate among Pinus monticola near Ladys.mith, British Columbia. Heredity, 58, 173-181.

ELLSTRAND, N. C. AND FOSTER, K. W. 1983. Impact of population structure on the apparent outcrossing rate of grain sorghum (Sorghum bicolor). Theor. Appl. Genet., 66, 323327.

ENNOS, R. A. 1985. The mating system and genetic structure in a perennial grass, Cynosurus cristatus L. Heredity, 55, 121 126.

ENNOS, R. A. AND CLEGG, M. T. 1982. Effect of population substructuring on estimates of outcrossing rate in plant populations. Heredity, 48, 283-292. 
FOR1), H. A., PATON, D. C. AND FORDE, N. 1979. Birds as pollinators of Australian plants. N. Z. J. Bot., 17, 509-519.

FRIPP, Y. J. 1982. Allozyme variation and mating system in two populations of Eucalyptus kitsoniana (Luehm.) Maiden. Aust. For. Res., 13, 1-10.

FRIPP, Y. J., GRIFFIN. A. R. AND MORAN, G. F. 1987. Variation in allele frequencies in the outcross pollen pool of Eucalyptus regnans F. Muell. Throughout a flowering season. Heredity, 59, 161-171.

FURNIER, G. R. AND ADAMS, W. T. 1986. Mating system in natural populations of Jeffrey pine. Amer. J. Bot., 73, 1002 1009.

FURNIER, G. R., KNOWLF.S, P., CLYDE, M. A. ANI) DAN(IK, B. P. 1987. Effects of avian seed dispersal on the genetic structure of whitebark pine populations. Evolution, 41, $607-612$.

FYFE, J. L. AND BAILEY. N. T. J. 1951. Plant breeding studies in leguminous forage crops. 1. Natural cross-breeding in winter beans. J. Agric. Sci., 41, 371-378.

GREGORIUS, H.-R., KRAUHAUSEN, J. AND MULLER-STARK, G. 1986. Spatial and temporal differentiation among the seed in a stand of Fagus sylvatica L. Heredity, 57, 255-262.

HEDRICK, P. W., JAIN, S. AND HOLDEN, L. 1978. Multilocus systems in evolution. Evol. Biol, 11, 101-182.

HOPPER, S. D. 1981 . Honeyeaters and their winter food plants on granite rocks in the central wheatbelt of Western Australia. Aust. Wildl. Res., 8, 187-197.

HOPPER, S. D. AND MORAN, G. F. 1981. Bird pollination and the mating system of Eucalyptus stoatei. Aust. J. Bot., 29, $625-638$

JAMES, S. H. 1965. Complex hybridity in Isotoma petraea. I. The occurrence of interchange heterozygosity, autogamy and a balanced lethal system. Heredity, 20, 341-353.

JAMFS, S. H. 1970. Complex hybridity in Isotoma petraea. 11. Components and operation of a possible evolutionary mechanism. Heredity, 25, 53-78.

JAMES, S. H. 1981. Cytoevolutionary patterns, genetic systems and the phytogeography of Australia. In Pate, J. S. and McComb. A. J. (eds.) Ecological Biogeography of Australia, Junk, The Hague, pp. 761-782.

JAMES, S. H. AND HOPPER, S. D. 1981. Speciation in the Australian flora. In Keast, A. (ed.) The Biology of Australian Plants, University of Western Australia Press, Nedlands, pp. $361-381$

KNOWLES, P. 1984. Genetic variability among and within closely spaced populations of lodgepole pine. Can. J. Genet. Cytol., 26, 177-184.

LEVIN, D. A. 1981. Dispersal versus gene flow in plants. Ann. Mo. Bot. Gard., 68, 233-253.

IEVIN, D. A. AND KERSIER, H. W. 1974. Gene flow in seed plants. In Dobzhansky, T., Hecht, M. K. and Steere, W. D. (eds.) Evolutionary Biology, Plenum Press, New York, pp. 139-220.

LINHART, Y, B., MITION, J. B., STURGEON, K. B. AND DAVIS, M. L. 1981. An analysis of genetic architecture in populations of Ponderosa pine. In Conkle, M. T. (ed.) Isozymes of North American Forest Trees and Forest Insects, U.S. Department of Agriculture, Berkeley, pp. 53-59.

LOVELESS, M. D. AND HAMRICK, J. L. 1984 Ecological determinants of genetic structure in plant populations. Ann. Rev. Fcol. Sust., 15, 65-95.

MCNEE, S. 1986. Grad. Dip. Nat. Res. Thesis, Curtin University. MORAN, G. F. AND BELl., J. C. 1983. Eucalyptus. In Tanksley, S. D. and Orton, T. J. (eds.) Isozvmes in Plant Genetics and Breeding, Elsevier, Amsterdam, pp. 423-441.

MORAN, G. F. ANI) BROWN, A. H. D. 1980. Temporal heterogeneity of outcrossing rates in alpine ash (Eucalyptus delagatensis R. T. Bak.). Theor. Appl. Genet., 57, 101-105.
MORAN, (j. F. AND HOPPER, S. D. 1983. Genetic diversity and the insular population structure of the rare granite rock species, Eucalyptus caesia Benth. Aust. J. Bot., 31, $162-172$.

MORAN, G. F. AND HOPPER, S. D. 1987. Conservation of the genetic resources of rare and widespread eucalypts in remnant vegetation. In Saunders, D. A., Arnold, G. W., Burbidge, A. A. and Hopkins, A. J. M. (eds.) Nature Conservation: The Role of Remnants of Native Vegetation, Surrey Beatty and Sons, Australia, pp. 151-162.

NEALE, D. B. AND ADAMS, W. T. 1985. The mating system in natural and shelterwood stands of Douglas-fir. Theor. Appl Genet., 71, 201-207.

NEI, M. 1973. Analysis of gene diversity in subdivided populations. Proc. Natl. Acad. Sci. U.S.A., 70, 3321-3323.

OMALLEY, D. M. ANI BAWA, K. S. 1987. Mating system of a tropical rain forest tree species. Amer. J. Bot., 74, 1143 1149.

PATON, D. C. AND FORD, H. A. 1977. Pollination by birds of native plants in South Australia. Emu, 77, 73-85.

PHILlips, M. A. AND BROWN. A. H. D. 1977. Mating system and hybridity in Eucalyptus pauciflora. Aust. J. Biol. Sci., 30, 337-344.

PRYOR, L.. D. AND JOHNSON, L. A. S. 1971. A classification of the Euculypts. Australian National University Press, Canberra.

RAO, C. R. 1973. Linear Statistical Inference and its Applications. Wiley, New York.

RITLAND, K. AND GANDERS, F. R. 1985. Variation in the mating system of Bidens menzeiesii (Asteraceae) in relation to population substructure. Heredity, 55, 235-244.

RITLAND, K. AND JAIN, S. 1981. A model for the estimation of outcrossing rate and gene frequencies using $n$ independent loci. Heredity, 47, 35-52.

SAMPSON, J. F. 1988. Ph.D. Thesis, The University of Western Australia.

SAMPSON, J. F., HOPPER, S. D. AND JAMES, S. H. 1988. Genetic diversity and the conservation of Eucalyptus crucis Maiden. Aust. J. Bot, 36, 447-460.

SCHAAL, B. A. 1975. Population structure and local differentiation in Liatris cylindracea. Am Nat., 109, 511-528.

SC.HEMSKF, D. W. AND LANI)E, R. 1985. The evolution of self-fertilization and inbreeding depression in plants. II. Empirical observations. Evolution, 39, 41-52.

SCHOEN, D. S. AND CLEGG, M. T. 1984. Estimation of mating system parameters when outcrossing events are correlated. Proc. Natl. Acad. Sci. U.S.A., 81, 5258-5262.

SHAW, D. V. AND ALLARD, R. W. 1981. Analysis of mating system parameters and population structure in Douglas-fir using single-locus and multilocus methods. In Conkle, $M$. T. (ed.) Isozymes of North American Forest Trees and Forest Insects, U.S. Department of Agriculture, Berkeley, pp. 1822.

SHAW, D. V. AND ALlARD, R. W. 1982. Estimation of outcrossing rates in Douglas-fir using isozyme markers. Theor. Appl. Genet., 62, 113-120.

SHEA, K. L. 1987. Effects of population structure and cone production on outcrossing rates in Engelmann spruce and subalpine fir. Evolution, 41, 124-136.

TIJRNER, M. E., CLAIBOURNE STEPHENS, J. ANI) ANIDERSON, W. W. 1982. Homozygosity and patch structure in plant populations as a result of nearest-neighbour pollination. Proc. Natl Acad. Sci. USA, 79, 203-207.

WASER, N. M. 1987. Spatial genetic heterogeneity in a population of the montane perrenial plant Delphinium nelsonii. Heredity, 58, 249-256.

WEIR, B. S. 1979. Inferences about linkage disequilibrium. Bio metrics, 35, 235-254. 
WEIR, B. S. AND COCKERHAM, C. C. 1979. Estimation of linkage disequilibrium in randomly mating populations. Heredity, 42, 205-222.

Wellington, A. B., POlach, H. A. AND NOBle, I. R. 1979. Radiocarbon dating of lignotubers from mallee forms of Eucalyptus. Search, 10, 7-8.

WORKMAN, P. L. AND NISWANDER, J. D. 1970. Population studies on southwestern Indian tribes. II. Local genetic differentiation in the Papago. Am. J. Hum. Genet., 22, 24-49.
WRIGHT, S. 1969. Evolution and the Genetics of Populations. Vol. 2, The Theory of Gene Frequencies. University of Chicago Press, Chicago.

YEH, F. C., BRUNE, A., CHELIAK, W. M. AND CHIPMAN, D. C. 1983. Mating system of Eucalyptus citriodora in a seed production area. Can. J. For. Res., 13, 1051-1055. 